\title{
Development and use of Bacteroides 16S rRNA Polymerase Chain Reaction Assay for Source Tracking Dog Faecal Pollution in Bathing Waters
}

\author{
Khwam R. Hussein ${ }^{1,3 *}$, Paul L. Waines ${ }^{1}$, Raid B. Nisr ${ }^{1}$, Gillian Glegg ${ }^{2}$ and Graham Bradley ${ }^{1}$
}

${ }^{1}$ School of Biological Sciences, Plymouth University, PL4 8AA, UK

${ }^{2}$ School of Marine Sciences and Engineering, Plymouth University, PL4 8AA, UK

${ }^{3}$ Al- Nasiriya Medical Institute, Foundation of Technical Education, Post code- 64001, Iraq

\begin{abstract}
Faecal pollution on bathing beaches poses a potential threat to human health and as a result may also negatively affect the local economy. In instances where the source of such pollution is not obvious, it may be necessary to track such sources using a host-specific genetic markers technique. Bacteroides species are potential indicators for source tracking of faecal pollution in bathing waters. This study designed specific primer sets to amplify sections of the 16S rRNA gene unique to Bacteroides from domestic dogs and used quantitative PCR (qPCR) to quantify such genetic markers in environmental samples. The sensitivity and specificity of the primer sets was determined; they were specific in silico against known dog Bacteroides sequences and in vitro against Bacteroides sequences originating from human and livestock faeces. Dog faecal Bacteroides contamination was then detected in sea water during the bathing season at a local beach where dogs are banned during the summer months, in spite of the fact that these waters had met EU directive standards based on the culture-based enumeration of faecal indicator bacteria. Quantitative PCR was used to determine the limit of detection (LOD) of the dog Bacteroides genetic markers in these water samples. The copy number of dog Bacteroides genetic markers in the water was low and the LOD of those markers was 4 copies per reaction. The use of these dog primers has the potential to supply important additional information when source tracking faecal pollution at bathing beaches and maintaining water quality.
\end{abstract}

Keywords: $16 \mathrm{~S}$ rRNA marker; Dog-specific Bacteroides primer; Bathing water pollution

\section{Introduction}

Faecal indicator bacteria (FIB) such as Escherichia coli (E. coli) and Enterococci are currently used to determine faecal bathing water pollution; they are found in a variety of warm-blooded animals and are not unique to the intestinal flora of humans [1]. Determining the exact sources of faecal pollution is now of critical importance when attempting to comply with the EU bathing water directive 2006 [2]. Bacteria belonging to the genus Bacteroides are now used as additional source-tracking indicator bacteria, since they constitute a major part of the faecal bacterial population; as strict anaerobes they have little potential for growth in bathing waters and have a high degree of host specificity $[3,4]$. Non-culture based, Bacteroides-based tracking methodologies are designed to target specific sequences within the Bacteroides 16S rRNA gene in order to differentiate human-derived contamination from that of other animals $[5,6]$. The most commonly used tools for such studies are conventional PCR-based analysis [7] and quantitative PCR (qPCR) [8]. Coastal waters are frequently used for a variety of recreational and commercial activities. Faecal pollution may thus arise not only from human sources but also from farm livestock and other animals, which may contribute additional pathogens to bathing waters, including viruses and bacteria [9]. In urban areas there are many sources that may lead to the contamination of water supplies, such as urban runoff and negligent waste management, as well as discharge from domestic pets; these represent important potential sources of faecal pollution in aquatic systems [10-12]. In developed countries, the populations of domestic dogs (canis lupus familiaris) have grown significantly over the last two decades [13]. For example, according to a public survey the number of dogs in the UK is about 9.4 million [14]. Dog faeces that are not correctly disposed of can be washed directly by surface runoff into water systems. Moreover, dog faecal pollution poses a possible threat to public health because of the potential transmission to humans of zoonotic microbes [15-17]; such microbes can inhabit apparently healthy domestic dogs $[12,18,19]$.
Dogs are now banned from various UK bathing beaches during the bathing season but there is currently no simple and/or inexpensive method for source-tracking faecal pollution from dogs on beaches and thus accurately assessing the actual effectiveness of such bans is difficult. Kildare et al. [4] have previously designed TaqMan labelled assays to quantify dog-specific Bacteroides. In the current study, the authors report the development and use of specific and sensitive conventional PCR primer sets and qPCR assays based on SYBR' green fluorescent binding dye. Thus, this study aimed to design and test hostspecific PCR primer sets to amplify a section of the 16S rRNA gene unique to Bacteroides spp. originating from dog faeces and to further determine the specificity and the sensitivity of these markers in bathing waters from two UK beaches with differing seasonal dog bans.

\section{Materials and methods}

\section{Sampling and DNA extraction}

Fifty eight faecal samples (10 dogs, 12 cows, eight horses, four pigs, eight sheep, four deer, two cats and six ducks) were collected from local sources in Devon, UK and four human faecal samples were obtained from adult volunteers. DNA was extracted from faecal samples (200 mg) using a QIA ampstool DNA mini kit (Qiagen, UK) according to

*Corresponding author: Khwam R. Hussein, School of Biological Sciences, Plymouth University, Plymouth, Devon, UK, Tel: 447981888193; E-mail: khwam.hussein@plymouth.ac.uk

Received December 18, 2013; Accepted January 20, 2014; Published January 24, 2014

Citation: Hussein KR, Waines PL, Nisr RB, Glegg G, Bradley G (2014) Development and use of Bacteroides 16S rRNA Polymerase Chain Reaction Assay for Source Tracking Dog Faecal Pollution in Bathing Waters. Hydrol Current Res 5 : 163. doi:10.4172/2157-7587.1000163

Copyright: ( 2014 Hussein KR, et al. This is an open-access article distributed under the terms of the Creative Commons Attribution License, which permits unrestricted use, distribution, and reproduction in any medium, provided the original author and source are credited. 
the manufacturer's instructions. A fresh buffered lysozyme solution $\left(500 \mu \mathrm{l} ; 50 \mathrm{mg} \mathrm{ml}^{-1}\right.$ Tris-EDTA, $\left.\mathrm{pH} 8.0\right)$ was added and samples were incubated at $37^{\circ} \mathrm{C}$ for $30 \mathrm{~min}$. After extraction, the DNA pellet was suspended in $100 \mu$ l elution buffer $(10 \mathrm{mM}$ Tris- $\mathrm{HCl}, 1 \mathrm{mM}$ EDTA, $\mathrm{pH} 8.0)$ and stored at $-80^{\circ} \mathrm{C}[20,21]$ until analysed. The purity and quantity of DNA samples was measured using a NanoVue" UV spectrophotometer (Fisher, UK).

\section{Conventional PCR}

PCR was used to detect the Bacteroides $16 \mathrm{~S}$ rRNA genetic marker in water, sediment and faecal samples by using previously reported generic Bacteroides forward (Bac32F) and reverse (Bac708R) primers $[5,6]$. In addition, HF183F, CF128F, HoF795F, PF163F primers $[5,6$, 22] were used to detect and differentiate human, cow, horse and pig genetic markers respectively in water and sediment samples (Table 1). PCR reactions were carried out in a total volume of $25 \mu \mathrm{l}$; each reaction mixture contained $2 \mu \mathrm{l}$ of extracted DNA, $1 \mu \mathrm{l}\left(50 \mathrm{p} \mathrm{mol} \mu^{-1}\right)$ of each of the forward and reverse primers (Eurofins, Germany), $8.5 \mu$ molecular

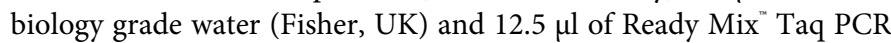
Reaction Mix (Sigma, UK). The cycling parameters were $15 \mathrm{~min}$ at $95^{\circ} \mathrm{C}$ for initial denaturation, followed by 35 cycles of $94^{\circ} \mathrm{C}$ for $30 \mathrm{~s}$, the annealing temperature for each primer for $30 \mathrm{~s}$ as is shown in Table 1, and $1 \mathrm{~min}$ at $72^{\circ} \mathrm{C}$, followed by a final extension step of $72^{\circ} \mathrm{C}$ for $6 \mathrm{~min}$ [5]. To detect the amplified products, $5 \mu$ laliquots of the PCR products were analysed using a gel composed of $1.5 \%$ agarose dissolved in $1 \times$ Tris-acetate EDTA buffer containing SYBR' Safe nucleic acid gel stain (Invitrogen, UK; concentration in accordance with the manufacturer's instructions), and run alongside a 50-1000 bp ladder (Sigma, UK). The PCR products derived from dog faecal samples were purified using the Sure Clean system (Bioline, UK) as described by the manufacturer's

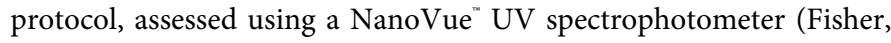
$\mathrm{UK}$ ), and then submitted for commercial sequencing.

\section{DNA sequencing and primer design}

The purified PCR amplicons of dog faecal Bacteroides obtained using the primer set Bac32F-Bac708R were commercially sequenced using the value read service from Genome Analysis and Technology Core (GATC Biotech, UK). Identification of Bacteroides spp. was performed by using the Basic Local Alignment Search Tool (BLAST) software from the National Centre for Biotechnology Information (NCBI). The NCBI-BLAST software was used to identify the DNA sequence identity and the evolutionary relationship between the $16 \mathrm{~S}$ rRNA genetic marker originating from dog faecal Bacteroides sp. and other animal sources (human, cow, horse, pig, cat and duck). A phylogenetic tree was created using the Molecular Evolutionary Genetics Analysis (MEGA) version 5.2.2 [23]. The evolutionary history was deduced by using the maximum likelihood method based on the Tamura-Nei model [24]. Clustalw2 software (www.ebi.ac.uk/ Tools/msa/clustalw2/) was also used to compare a multiple sequence alignment pattern between the faecal Bacteroides 16S rRNA genetic marker sequences originating from dog faeces and those from non-dog sources to assign these marker sequences to operational taxonomic units (OTUs). OTUs were defined by assigning $16 \mathrm{~S}$ rRNA sequences with a $>98 \%$ similarity to other sequences to the same species $[25,26]$. The mismatching sequence regions of the 16S rRNA genetic marker were then utilized to design specific primers for dog faecal Bacteroides spp.

Three dog-specific primer sets were produced: DF53F-DF606R, DF113F-DF472R, and DF418F-DF609R (Table 2). These were used to amplify the $16 \mathrm{~S}$ rRNA genetic marker of dog Bacteroides using the PCR parameters previously described above; the annealing temperature was optimized using different temperatures $\left(55,57,60,62.5\right.$ and $\left.65^{\circ} \mathrm{C}\right)$ for each primer set. Each set was also used to attempt to amplify $16 \mathrm{~S}$ rRNA genetic markers from total DNA isolated from human, cow, pig, horse, sheep, deer, cat, and duck faecal samples. Primer sets were also used to interrogate the GenBank database for known Bacteroides sequences from dog and non-dog faeces.

\section{Culture based analysis of FIB and the detection of the dog Bacteroides 16S rRNA genetic marker in bathing water}

Bigbury-on-Sea beach is situated on either side of a tidal isthmus at the lower reach of the Avon estuary in south west England (latitude $50.28^{\circ} \mathrm{N}$ longitude $-3.89^{\circ} \mathrm{W}$ ). This area was selected because it is a very popular beach for human recreational activities including dog walking, bathing and surfing. The sandy isthmus is divided into two sites: ' $\mathrm{A}$ ' an area where dogs are allowed access all year and ' $\mathrm{B}$ ' an area where dogsare banned in the summer months (Figure 1). Triplicate water and sediment samples were collected on three occasions from each of the study areas in wide-mouth 500 or $50 \mathrm{ml}$ containers for water and sediment respectively, at a depth of approximately $30 \mathrm{~cm}$ below the water surface or from the sediment on the beach. Three sampling events were performed at intervals of about two weeks in July and in

\begin{tabular}{|c|c|c|c|c|c|}
\hline Primers & Primer sequences $\quad\left(5^{\prime} . . . . . .3^{\prime}\right)$ & Annealing temp. ${ }^{\circ} \mathrm{C}$ & Host of Bacteroides & Amplicon size (bp) & References \\
\hline Bac32F & AACGCTAGCTACAGGCTT & 53.7 & General & 670 & \multirow{4}{*}{$\begin{array}{c}{[5]} \\
{[5]} \\
{[5]} \\
{[23]}\end{array}$} \\
\hline HF183F & ATCATGAGTTCACATGTCCG & 55.3 & Human & 520 & \\
\hline CF128F & CCAACYTTCCCGWTACTC* & 54.8 & Cow & 580 & \\
\hline HoF795F & GCGGATTAATACCGTATGA & 56.7 & Horse & 129 & \\
\hline PF163F & CCAGCCGTAAAATAGTCGG & 52.4 & Pig & 563 & \multirow{2}{*}{$\begin{array}{c}{[23]} \\
{[5]}\end{array}$} \\
\hline Bac708R & CAATCGGAGTTCTTCGTG & - & - & - & \\
\hline
\end{tabular}

${ }^{*} \mathrm{~W}$ : A or T, Y:C or T, Bac708R: reverse primer

Table 1: The previously designed host-specific Bacteroides primers used in this study, all forward primers were coupled with reverse primer Bac708R.

\begin{tabular}{|c|c|c|c|c|}
\hline Primers & Primer sequences (5' ----3') & Length (bp) & Amplicon size (bp) & Annealing temp. ${ }^{\circ} \mathrm{C}$ \\
\hline DF53F & TATCCAACCTCCCGCATAC & \multirow{6}{*}{$\begin{array}{l}19 \\
19 \\
19 \\
20 \\
20 \\
18\end{array}$} & \multirow{2}{*}{570} & \multirow[b]{2}{*}{62.5} \\
\hline DF606R & CATTTCACCGCTACACCAC & & & \\
\hline DF113F & ATCTCAAGAGCACATGCAA & & \multirow{2}{*}{380} & \multirow{2}{*}{62.5} \\
\hline DF472R & AATAAATCCGGATAACGCTC & & & \\
\hline DF418F & ACGAATAAGCATCGGCTAAC & & \multirow{2}{*}{210} & \multirow[t]{2}{*}{63.5} \\
\hline DF609R & AAGCATTTCACCGCTACA & & & \\
\hline
\end{tabular}

Table 2: Dog-specific faecal Bacteroides primer sets designed in this study. 


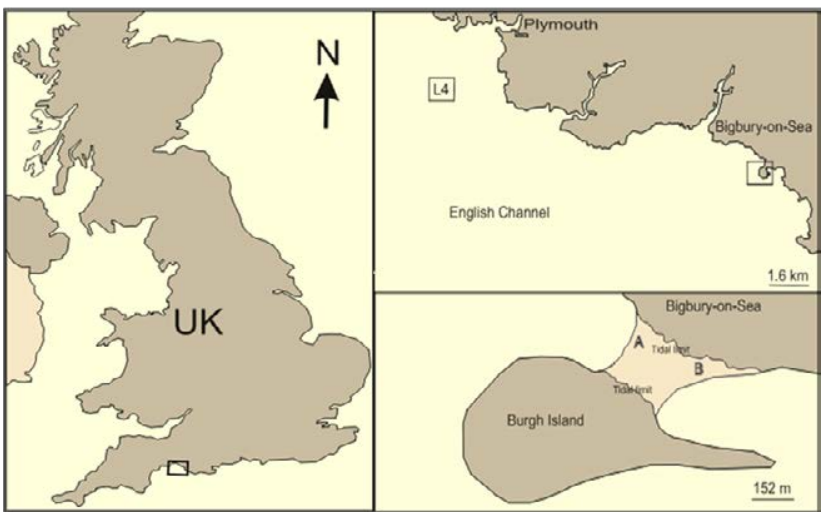

Figure 1: The sampling stations on Bigbury-on-Sea beach, Devon, UK. A: an area where dogs are permitted access all year, B: an area where dogs are banned in summer months, L4: L4 Plymouth off-shore station.

August 2012. Water samples were also collected from the Plymouth off-shore station L4 (7 miles off the Plymouth coast $\left.50.15^{\circ} \mathrm{N}-4.13^{\circ} \mathrm{W}\right)$ to use as a dog faecal pollution-free control in all tests. The water and sediment samples were returned to the laboratory and the examination was conducted within six hours of collection [27]. The membrane filtration method (using Whatman $47 \mathrm{~mm}, 0.45 \mu \mathrm{m}$ pore size cellulose nitrate membrane filters) was used for detection and enumeration of $\mathrm{E}$. coli, Enterococci and Bacteroide sp. as described by Hussein et al. [28] for both the water $(100 \mathrm{ml})$ and sediment samples. Sediment $(2$ gram wet weight) was suspended in $18 \mathrm{ml}$ sterile seawater, vortex mixed for two minutes, and then left to settle for $10 \mathrm{~min}$ before aspiration of the supernatant. The filter membranes were placed on to solid media or an absorbent pad soaked with broth as described below [29-31]. Membranes were placed onto Slanetz and Bartley agar for Enterococci culture and enumeration [32]; membrane lauryl sulphate broth to detect E. coli [33]; and on Bacteroides bile esculin agar to detect Bacteroides spp. [34]. E. coli and Enterococci cultures were incubated at $35^{\circ} \mathrm{C}$ for $4 \mathrm{~h}$ for resuscitation of cells. Enterococci cultures were then incubated at $44^{\circ} \mathrm{C}$ for $44 \mathrm{~h}$ [32], and E. coli cultures were incubated overnight at $44^{\circ} \mathrm{C}$ [35]. Bacteroides cultures were incubated at $37^{\circ} \mathrm{C}$ for $72 \mathrm{~h}$ in an anaerobic chamber (Don Whitley, UK). The numbers of FIB and faecal Bacteroides from the water and wet sediment samples were expressed as colony forming units (CFU) $100 \mathrm{ml}^{-1}$ water and CFU g ${ }^{-1}$ sediment, respectively [29]. DNA was extracted from water $(300 \mathrm{ml})$ using a QIAamp stool DNA mini kit (Qiagen, UK), and wet sediment samples $(200 \mathrm{mg})$ using a Soil Master ${ }^{\mathrm{TM}}$ DNA extraction kit (Cambio, UK) respectively, according to the manufacturers' protocols. Conventional PCR was then performed as described previously for the animal Bacteroides-specific primer sets using the annealing temperatures given in Tables 1 and 2. To create an absolute standard curve, PCR insert products (DF418F-DF609R and DF113FDF472R dog Bacteroides primer sets) were purified and ligated into the pGEM $^{\circ}$-T easy plasmid vector $3015 \mathrm{bp}$ (Promega, UK), according to the manufacturer's instructions. The ligated products were transformed into high efficiency E. coli JM109 competent cells (Promega, UK) and plated onto Luria-Bertani (LB) agar plates containing $40 \mu \mathrm{g} \mathrm{ml}^{-1}$ $\mathrm{X}$-gal (5-bromo-4-chloro-3-indolyl- $\beta$-D-galactoside), $0.1 \mathrm{mM} \mathrm{IPTG}$ (Isopropyl- $\beta$-thiogalcto-pyranoside) and $100 \mu \mathrm{g} \mathrm{ml}$ ampicillin as recommended by the manufacturer (Promega, UK). Plasmid DNA was extracted from the culture of recombinant E. coli using a GenElute ${ }^{\mathrm{TM}}$ Plasmid Miniprep kit (Sigma, UK). PCR was also used to amplify the 16S rRNA genetic marker inserts from recombinant plasmids and the products visualized by gel electrophoresis. Partial sequencing was performed commercially (GATC, UK) and the resulting sequences were subjected to BLAST analysis on the GenBank (NCBI) public database to find the closest-aligning sequences to the target 16S rRNA genetic marker. The reaction of qPCR was then performed in a total reaction volume of $25 \mu \mathrm{l}$. The two dog-specific Bacteroides primer sets (DF113FDF472R and DF418F-DF609R) were used in the qPCR assay and the third set (DF53F-DF606R) was used in conventional PCR because its high product size prevented its use in $\mathrm{qPCR}$. Each reaction contained $12.5 \mu \mathrm{l}$ SYBR $^{\circ}$ Green 1 JumpStart Taq ReadyMix (Sigma, UK), $1 \mu \mathrm{l}$ of each forward and reverse primer $(20 \mathrm{p} \mathrm{mol}), 0.25 \mu \mathrm{l}$ ROX reference dye (Invitrogen UK), $8.25 \mu$ RNase/DNase-free water (Fisher, UK) and $2 \mu \mathrm{l}$ template DNA. The mixture was applied to a MicroAmp Optical 96-well reaction plate, covered tightly with adhesive film, and then run in the Step One Plus real-time PCR system (Applied Bio systems, USA) using 40 cycles of $15 \mathrm{~s}$ denaturation at $94^{\circ} \mathrm{C}, 1 \mathrm{~min}$ annealing at 62.5 or $63.5^{\circ} \mathrm{C}$ (Table 2), and 1 min extension at $72^{\circ} \mathrm{C}$. Melting curves for PCR products were set between $60-90^{\circ} \mathrm{C}$ with a resolution of $0.3^{\circ} \mathrm{C}$ after cycling to determine amplification specificity. Triplicate amplifications of a positive (Bacteroides-plasmid) and a negative (notemplate) control were used for quality control, the latter containing seawater samples from the Plymouth L4 (dog-free) offshore station. A tenfold dilution series of recombinant pGEM-T plasmid containing the target sequence of the genetic marker was prepared, to create absolute standard curves ranging from $5 \times 10^{6}$ to $5 \times 10^{0}$ copies [36]. For the evaluation of dog-specific Bacteroides primer sensitivities and PCR amplification among the experiments, the slope of the standard curves were determined by performing a linear regression testing with StepOne" Software v 2.2.2 (Applied Biosystems, USA). For qPCR standards, the concentration was plotted against the cycle number at which the fluorescence signal exceeded the threshold cycle (Ct value). The efficiency of amplification (Eff.) was determined by the slope of the standard curve and calculated using the following equation: Eff $=\left(10^{-1 / \text { slope }}\right)-1[37,38]$. The concentration of DNA or copy number of unknown samples was calculated using the following equation: $[\mathrm{DNA}]=10^{\mathrm{Ct}-\mathrm{b} / \mathrm{s}}[39]$, where $\mathrm{b}$ is the Y-Intercept and $\mathrm{s}$ is the slope. Water and sediment DNA samples were categorized as positive when the melting points were matched with the melting point of the standard curve amplification with a tolerance of $0.5^{\circ} \mathrm{C}[40]$.

\section{Quantitative PCR determination of the limit of detection}

The limit of detection (LOD) is defined as the lowest amount of measurable target in a single reaction $[40,41]$. This was determined using serial dilutions of the sample $\left(10^{-1}-10^{-8}\right)$, extracting DNA from each dilution and then analysing this using conventional PCR and qPCR. The number of culturable Bacteroides was enumerated using the membrane filtration method for each dilution. Klappenbach et al. [42] stated that in the ribosomal DNA operon copy number database, the $B$. fragilis carries six 16S rRNA operons per cell. Thus, the genomic DNA mass of $B$. fragilis NCTC 9343 in this study was determined as $9.49 \times 10^{-4} \mathrm{pg}$. The plasmid DNA (plasmid and insert) mass per copy was also calculated as $3.5 \times 10^{-6} \mathrm{pg}$ using the average molecular weight of double-strand DNA bp as 660 Dalton $[37,43]$. The sequences of the dog-specific Bacteroides 16S rRNA genetic markers determined in this study have been deposited in the GenBank under accession numbers JX431865-JX431867.

\section{Statistical analysis}

Results were statistically analysed using the SPSS statistical programme version 20. One way analysis of variance (ANOVA) was carried out in order to determine both significance of differences between the numbers of FIB isolated, and the statistical differences 
between the Ct values (in triplicate for each run) of DNA which were obtained from water and sediment samples as well as those obtained from non-template DNA. To calculate the effectiveness of the new dog-specific primers using conventional PCR, sensitivity (sn\%) and specificity $(\mathrm{sp} \%)$ were determined as $\mathrm{sn}=\mathrm{a} /(\mathrm{a}+\mathrm{c})$ and $\mathrm{sp}=\mathrm{d} /(\mathrm{d}+\mathrm{b})$, where $\mathrm{a}$ is a positive faecal sample for the genetic marker of its target species (true positive); $b$ is a positive faecal sample for another genetic marker (false positive); $c$ is a negative faecal sample for a genetic marker its target species (false negative); $d$ is a negative for genetic marker of another species (true negative) [44], and sn/sp values of 1 corresponded to $100 \%$. A p value equal to or less than 0.05 was considered to indicate a significant difference.

\section{Results}

\section{Specific primer design for $16 \mathrm{~S}$ rRNA genetic marker of dog faecal Bacteroides}

A section of the Bacteroides 16S rRNA gene from 58 animal faecal samples mentioned above was successfully amplified from faeces by using the generic Bacteroides primer set (Bac32F-Bac708R). PCR yielded amplification of a unique Bacteroides $16 \mathrm{~S}$ rRNA genetic marker of $670 \mathrm{bp}$ (Figure 2a). The sequences from Bacteroides 16S rRNA genetic markers amplified from both dog faeces and isolated cultures of dog faecal Bacteroides were used to design specific primer sets differentiating 16S rRNA genetic marker amplicons of dog Bacteroides species from other animal Bacteroides genetic markers. Three sets of dog-specific primers were designed. The annealing temperature of each of the primer sets DF53F-DF606R, DF113FDF472R, and DF418F-DF609R was optimized (Table 2) and the PCR produced signal bands of the expected size for the primer set in each case (570, 380 and 210 bp respectively). The first primer set DF53FDF606R yielded a single band from dog faecal DNA samples, whereas no products were detected from DNA faecal samples of humans and other animals (Figure 2b). The second set, DF113F-DF472R, showed a similar result (Figure 2c). However, PCR amplification reactions using the third set (DF418F-DF609R), whilst showing a strong positive band with dog faecal Bacteroides DNA, also produced a weak band when human faecal Bacteroides template DNA was used; no bands were observed in the case of all other animal faecal Bacteroides DNA (Figure 2d). When designing dog-specific faecal Bacteroides primers, faecal Bacteroides sequences were tested using (i) the partial Bacteroides $16 \mathrm{~S}$ rRNA genetic marker sequences obtained from dog faeces (accession numbers JX431865-JX431867) and (ii) partial Bacteroides 16S rRNA genetic marker sequences of other faecal sources obtained through interrogation of the GenBank database (in silico). Seventy two OTUs were closely related (similarity $98 \%$ or greater) to the three dog specific Bacteroides genetic markers (GenBank accession numbers JX431865JX431867) from dog faecal samples. These sequences were used to create a phylogenetic tree for displaying the evolutionary relationship between dog Bacteroides 16S rRNA genetic marker with non-dog Bacteroides genetic markers (Figure 3). In addition, the investigation of Bacteroides 16S rRNA genetic marker sequences showed a maximum similarity up to $89 \%$ between dog Bacteroides and non-dog Bacteroides genetic markers (Table 3). The sensitivity and specificity of the first and second dog-specific primers (DF53F-DF606R and DF113F-DF472R) was $100 \%$ due to the true positive of 10 out of $10 \mathrm{dog}$ faecal samples tested, and no reaction was seen in all other animal Bacteroides DNA (48 samples). However, the third primer set (DF418F-DF609R) gave a true positive in 10 out of 10 dog faecal samples (sensitivity 100\%) but it appeared as a true negative in 44 out of 48 other faecal samples (specificity 92\%).

\section{Standard curve and quantitative PCR}

The standard curve showed a linear slope and the quantity of the genetic marker was from 0 to $6 \log _{10}$ copy number of dog-specific Bacteroides genetic markers per micro litre of plasmid DNA extracted. The amplification efficiencies (Eff\%) of each qPCR run ranged between $91-114 \%$ for both genetic markers. The correlation coefficient $\left(\mathrm{R}^{2}\right)$ was between 0.925-0.982 (Figure 4). To distinguish the targeted PCR product from non-targeted product, a melting curve plot for the SYBR' primers was performed after qPCR amplification [37]. A qPCR reaction with slope -3.32 will produce $100 \%$ efficiency [38]. The limit of detection of qPCR was evaluated for both faecal dog Bacteroides primer sets at a dilution of $10^{-6}$, corresponding to a 4 target copy number per reaction and a concentration of $9.5 \times 10^{-5} \mathrm{ng}^{-1} \mathrm{l}^{-1}$, as calculated using the NanoVue ${ }^{\prime \prime}$ UV spectrophotometer as previously described.

\section{Culture of FIB and detection of dog faecal Bacteroides 16S rRNA genetic markers in bathing waters}

Culture-based analysis of the water and sediment samples for E. coli, Enterococci, and Bacteroides spp. on the three field visits at the two sites (A-dog permitted, B-dog banned) are shown in Figure 5. When E. coli and Enterococci results were compared to the EU bathing water directive 2006, $<200$ and $<500 \mathrm{CFU} 100 \mathrm{ml}^{-1}$ respectively, beach water quality was deemed safe for human contact. E. coli, Enterococci and Bacteroides were slightly higher in the beach water and sediment at the second sampling ( $15^{\text {th }}$ August 2012) compared with other sampling events. Overall, there was a significant difference in the total number of FIB between the sampling times $(p<0.001)$, whereas no significant difference was observed between sites $(\mathrm{p}=0.248)$. Neither FIB nor Bacteroides spp. were isolated in any of the water samples from the L4 offshore station. Three dog-specific primer sets (Table 2) were utilised
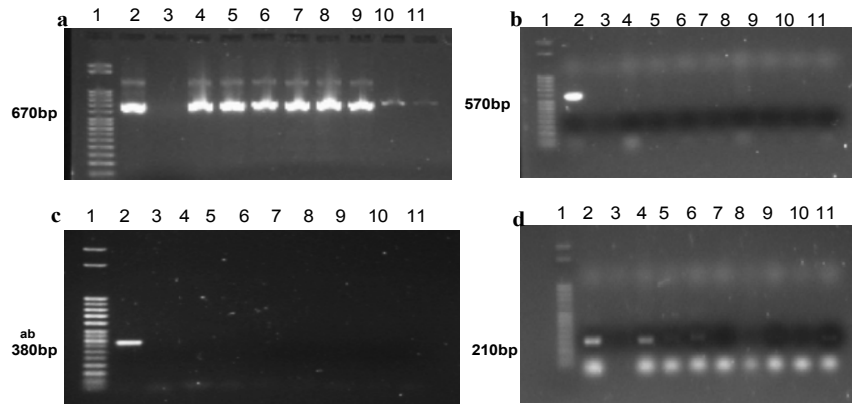

Figure 2: The amplification of Bacteroides 16S rRNA genetic markers isolated from the faeces of animals and humans using generic primer set Bac32F-Bac708R (a), and the dog-specific primer sets DF53F-DF606R (b) DF113F-DF472R (c), and DF418F-DF609R (d). Lane 1: 50-1000 bp ladder, lane 2: positive controls, lane 3: negative controls, lanes 4-11: human, cow, horse, pig, sheep, deer, cat and duck, respectively.

\begin{tabular}{|c|c|c|}
\hline Bacteroides hosts & Length (bp) & Similarity $\%$ \\
\hline Dog & 639 & 100 \\
\hline Human & 706 & 89 \\
\hline Cow & 700 & 87 \\
\hline Pig & 704 & 84 \\
\hline Duck & 638 & 82 \\
\hline Sheep & 707 & 87 \\
\hline Cat & 706 & 82 \\
\hline
\end{tabular}

Table 3: Comparison of sequence similarities between dog-specific Bacteroides (from amplicons obtained by PCR using dog-specific primer sets described in this study) and other host-specific Bacteroides sequence information obtained from the Genbank database. 


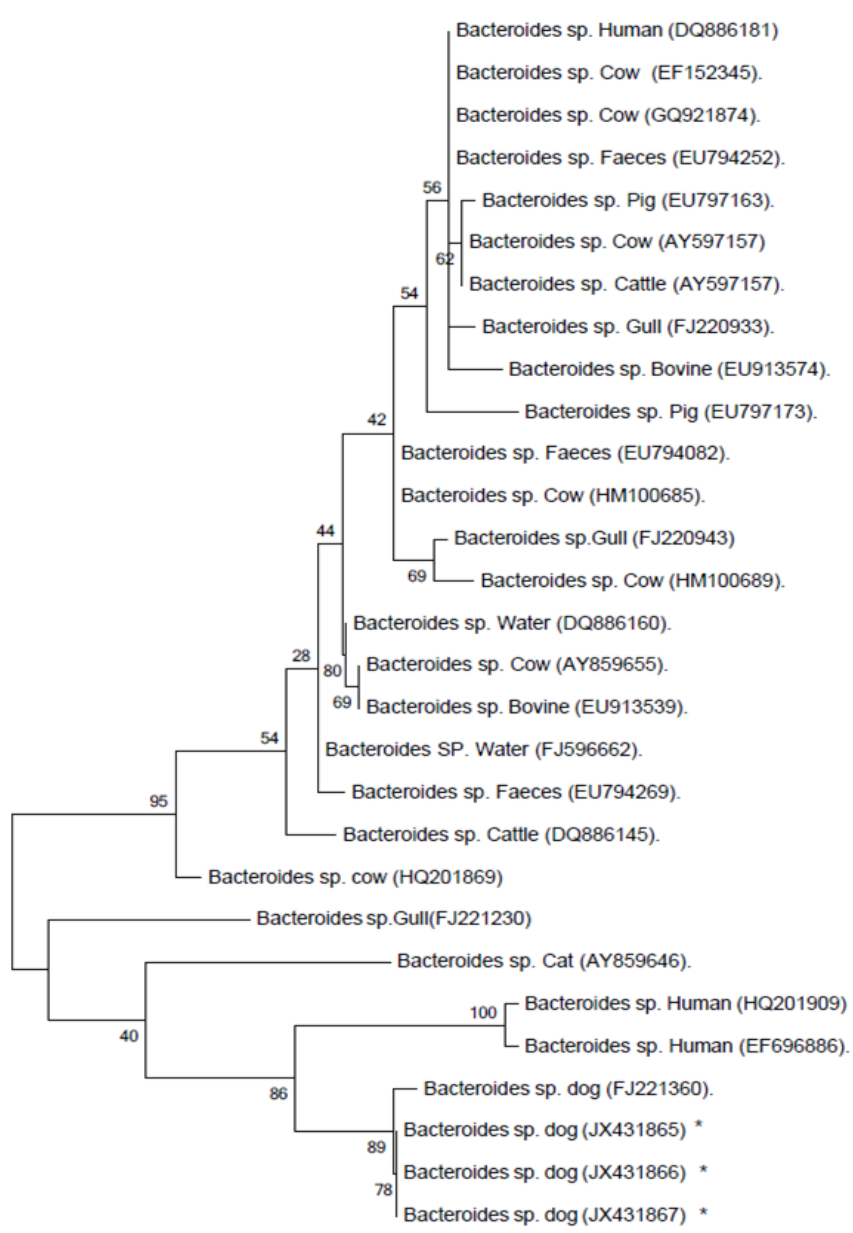

$\longmapsto .02$

Figure 3: The evolutionary relationships of host-specific Bacteroides associated with different animals, water and unknown faecal sources; phylogeny of the faecal Bacteroides 16S rRNA genetic markers was inferred by distance based analysis using Tamura-Nei distance estimates of aligned nucleotide sequences derived from the PCR sequence data. *Accession numbers of Bacteroides from dogs created in this study.

using conventional PCR to detect dog faecal Bacteroides genetic markers in the beach water and sediment of two sites at Bigbury-onSea. All primer sets showed positive results for genetic markers in the water samples from the two sites on two of the three sampling occasions. Using conventional PCR, no dog faecal genetic marker was detected in sediment at either site, although generic Bacteroides were detected. Faecal Bacteroides from human, horse and pig sources were not detected in any of the water or sediment samples, whilst positive results for cow Bacteroides genetic marker was observed in the water from site B (Table 4). Quantitative PCR assays were used to determine the copy number of dog faecal Bacteroides genetic markers in the water and sediment of beach samples. All copy numbers were relatively low, with the highest being in the water from the second survey (Figure 6). A significant correlation was observed between beach water site $A$ and site $B(r=0.951 ; p<0.05)$, but no correlation was identified between sediment $A$ and sediment $B(r=0.414 ; p>0.05)$.

\section{Discussion}

This report describes the design host-specific conventional and qPCR primers to target a 16S rRNA genetic marker of faecal Bacteroides unique to dogs. This may be used to source track faecal pollution resulting from dogs and to distinguish dog-derived faecal matter from that of other animal sources. The nucleotide sequence amplicons of dog Bacteroides amplified by the generic primers were aligned with $16 \mathrm{~S}$ rRNA gene sequences of Bacteroides from other animals in order to detect region(s) with strong mismatch sequences. This information was then used to design specific primers for the detection of dog-sourced Bacteroides. The mismatch effect of primer sequences of dog Bacteroides was investigated with non-target Bacteroides sequences from different sources, the primers showed

a

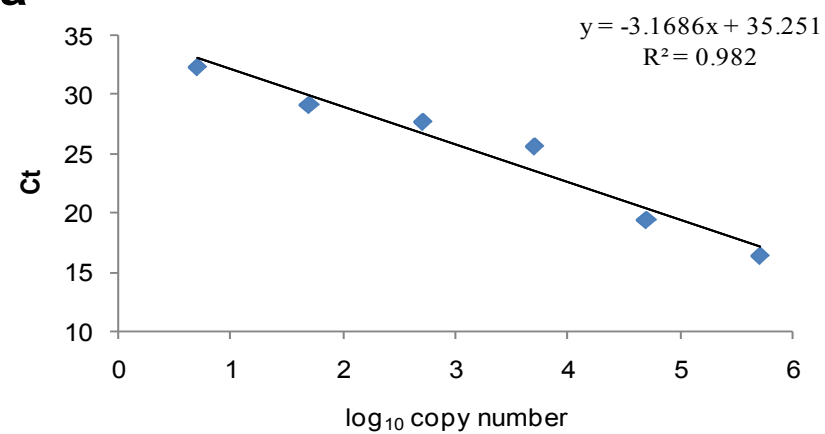

b

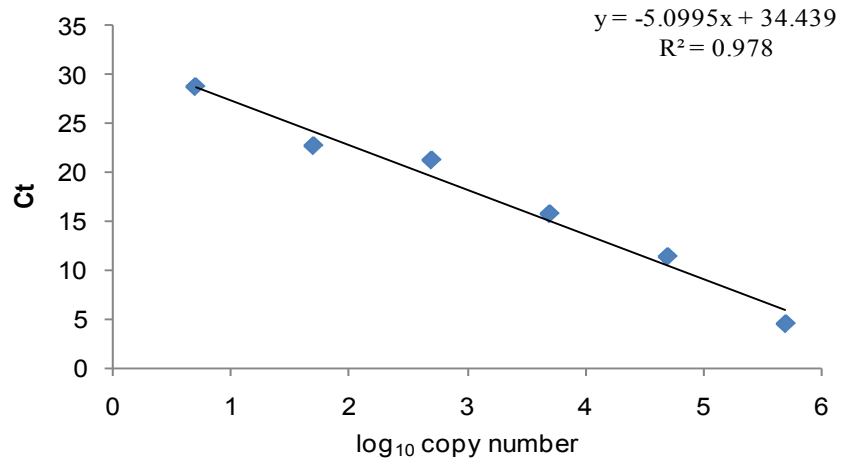

Figure 4: Standard curves created from tenfold serial dilution series of a recombinant pGEM-T plasmid containing the target sequence of the genetic marker, illustrating the threshold cycle (Ct) against $\log _{10}$ copy number measurements using dog-specific Bacteroides primer sets DF418F-DF609R (a) and DF113F-DF472R (b).

\begin{tabular}{|l|l|l|l|l|}
\hline *Primer sets of Bacteroides & \multicolumn{3}{l|l}{ Site A water / sediment } & \multicolumn{2}{l}{ Site B water / sediment } \\
\hline Bac32F-Bac708R & + & + & + & + \\
\hline HF183F-Bac708R & - & - & - & - \\
\hline CF128F-Bac708R & - & - & + & - \\
\hline HoF795F-Bac708R & - & - & - & - \\
\hline PF163F-Bac708R & - & - & - & - \\
\hline DF53F-DF606R & + & - & + & - \\
\hline DF113F-DF472R & + & - & + & - \\
\hline DF418F-DF609R & + & - & + & - \\
\hline
\end{tabular}

*Bac32: generic Bacteroides, HF: human, CF: cow, PF: pig, HoF: horse, DF: dog, Bac708R: reverse primer

Table 4: The detection host- specific Bacteroides genetic markers in the beach water and sediment on three sampling occasions during July and August 2012. $\mathrm{A}:$ an area where dogs are permitted access, $\mathrm{B}$ : an area where dogs are banned (Bigbury-on-Sea, Devon, UK). 


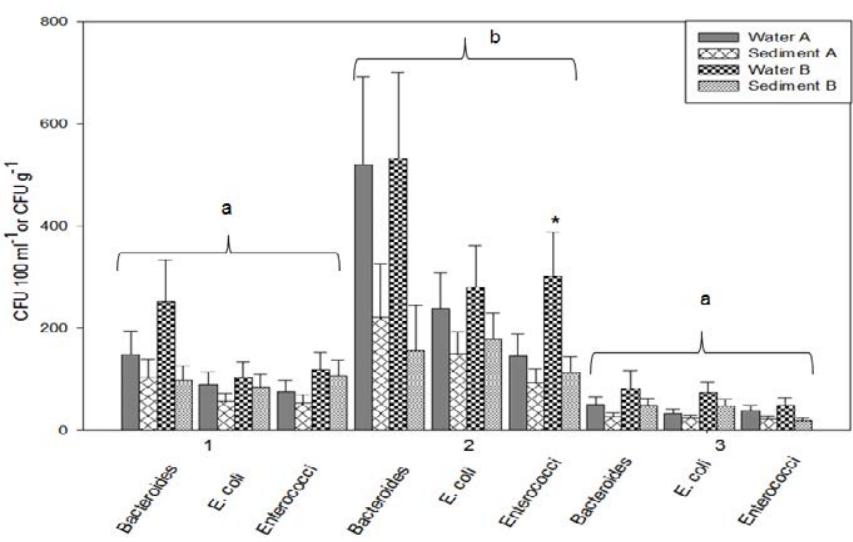

Figure 5: The distribution and frequency of Bacteroides spp., E. coli and Enterococci in the water and sediment from two sites A and B of the beach (mean and SE of triplicate sampling) at Bigbury-on-Sea. The numbers 1,2 and 3 indicate to samplings on $20^{\text {th }}$ July, $15^{\text {th }}$ and $30^{\text {th }}$ August 2012 , respectively. Different letters indicate a significant difference $(p<0.05)$. "The only breach (Enterococci) of the EU bathing water directive 2006.

3-11 oligonucleotide mismatches with all tested sequences. The amplified 16S rRNA genetic markers were sequenced and aligned with Bacteroides 16S rRNA gene sequences of other animals to determine the mismatched sequences which were used to design the dog-specific Bacteroides primers. The amplicon size and sequence of the conserved $16 \mathrm{~S}$ rRNA gene are very informative parameters that have been used phylogenetic studies in these species [45]. Specific PCR primers can be used for purposes such as phylogenetic analysis (to differentiate species in bacterial communities) and gene expression analysis [46]. Hall [23] demonstrated that phylogenetic trees can be used to analyse genetic and molecular similarity, mainly in DNA sequences, to achieve accurate information on the evolutionary associations of organisms. Phylogenetic analysis in this study was undertaken to explore the evolutionary relationships between Bacteroides from dog faeces and those of other animals including humans, and showed a high degree of relatedness regardless of the source (Figure 3). In the current study, distinguishing Bacteroides from dog faeces over Bacteroides from other sources, colonizing the same environment, was the major aim; this however is complicated by the fact that the $16 \mathrm{~S}$ rRNA gene of this genus exhibits a strong homology, and therefore primers designed to target a particular Bacteroides species can possibly detect other Bacteroides species [47]. All three primer sets appeared to have high sensitivity (100\%) and specificity (100, 100 and $92 \%$, respectively) in vitro and in silico and thus successfully detected the Bacteroides from dog faeces amongst Bacteroides from other sources. This compared favourably with BacCan-UCD assay [4] which showed $62.5 \%$ sensitivity. Some cross-reactivity was shown with human faecal Bacteroides PCR. This was because the similarity of nucleotide amplicons between the sequences of Bacteroides from dog and human faeces was a quite high $(89 \%)$, and the specificity of the thirdprimer set (DF418F-DF609R) was slightly below $100 \%$ (92\%). Other molecular methods such as denaturing gradient gel electrophoresis (DGGE) and next generation sequencing (NGS) have been used recently to distinguish sequences in closely similar species [48]. However, these techniques are relatively expensive compared with the method described here. In this study, SYBR' Green 1 fluorescent binding dye protocol was used in qPCR analysis to detect dog-specific Bacteroides genetic marker instead of the more expensive TaqMan protocol. SYBR ${ }^{\circ}$ Green 1 dye and TaqMan probe protocols have about the same limit of detection, reproducibility, and thermodynamic range, but the accumulation of primer dimers and the amplification of non-specific PCR products can be detected only in SYBR' Green 1 protocol [49]. When utilised on natural waters and sediments at a designated bathing beach at which dogs are both banned and permitted, all the water and the sediment samples showed positive results with the generic Bacteroides genetic markers indicating some degree of animal faecal pollution. However, no Bacteroides genetic markers from human, horse and pig origins were detected in any sample, although cow genetic markers showed some positive findings. The newly- designed dog-specific Bacteroides PCR primers identified products in water at both sites indicating the presence of dog faeces in the catchment of that coastal area. The results of qPCR showed that the dog Bacteroides genetic markers were present and could be detected in the beach waters and even in the beach sediments at both sites, although in low numbers. Low copy numbers, as well as variations in sensitivity and specificity associated with different genetic markers, have also been reported in other studies using human and other animal Bacteroides genetic markers [50], or other animal Bacteroides genetic primers [12, 37]. Culture-based results showed 'good/sufficient quality' of beach waters based on the EU bathing water directive 2006 for E. coli and Enterococci at both sites on each occasion. This study has therefore shown that even whilst water meets the requirements of the directive, pollution from dog faeces may still be present. In the past, the principal management measures in the event of the directive standards being breached have focused on sewage treatment facilities but, increasingly, it has been recognised that other diffuse sources of contamination may also be important. Therefore, knowledge of the source and longevity of bacteria found in bathing waters, as has been demonstrated for dogs in this study, is critical in order to manage the risks to human health. In conclusion, dog-specific Bacteroides PCR assays were designed and appear to be both specific and sensitive. The PCR primer sets designed in this study were successfully used to detect the presence of dog Bacteroides genetic markers in water from both areas of a bathing beach on which dogs were either banned or permitted. In this case, traditional FIB analysis methods found that the water quality was 'good', whereas source tracking demonstrated that Bacteroides sp. from dogs can even reach areas where access for dogs is restricted. Quantitative PCR assays with newly designed host-specific PCR primer sets were successfully developed and used for identification and quantification of dogspecific Bacteroides 16S rRNA genetic markers; this specificity cannot be achieved by culture-based methods. The use of such genetic markers to identify the source of bacteria in a case of a breach of the bathing

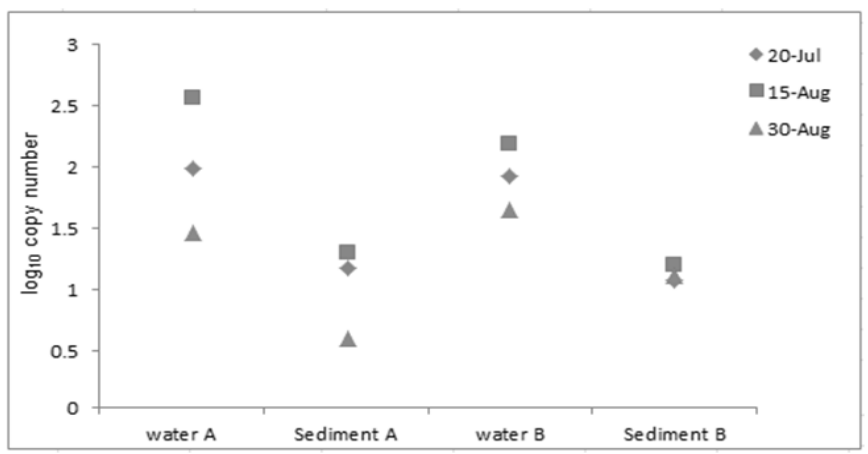

Figure 6: Mean copy numbers of dog-specific Bacteroides genetic markers found using primer sets (DF113F-DF472Rand DF418F-DF609R)in the water and sediment of the beach at Bigbury-on-Sea on three sampling occasions $\left(20^{\text {th }}\right.$ July, $15^{\text {th }}$ and $30^{\text {th }}$ August $\left.\Delta 2012\right)$ during the bathing season. A: an area where dogs are permitted access, B: an area where dogs are banned. 
water quality standards or an outbreak of disease may prove invaluable in future public health studies relating to faecal contamination of bathing water.

\section{Acknowledgements}

We would like to thank the Ministry of Higher Education and Scientific Research/Iraq for funding of this study. The authors are so thankful to Dr W. AbateWoldie from Plymouth University for technical assistance. We also thank Miss R. Brittain from the Marine Biological Association (MBA) Plymouth for helping to collect off-shore water samples.

\section{References}

1. Kreader CA (1995) Design and evaluation of Bacteroides DNA probes for the specific detection of human fecal pollution. Appl Environ Microbiol 61: 11711179

2. EU (2006) Directive 2006/7/EC of the European parliament and of the council of 15 February 2006 cocering the management of bathing water quality and repealing Directive 76/160/EEC. Offic J EU L64: 37-52.

3. Paster BJ, Dewhirst FE, Olsen I, Fraser GJ (1994) Phylogeny of Bacteroides, Prevotella, and Porphyromonas spp. and related bacteria. J Bacteriol 176: 725732

4. Kildare BJ, Leutenegger M, McSwain BS, Bambic DG, Rajal VB, Wuertz S (2007) : A Bayesian approach. Water Res 41: 3701-3715

5. Bernhard AE, Field KG (200) A PCR assay to discriminate human and ruminant feces on the basis of host differences in Bacteroides-Prevotella genes encoding 16S rRNA. Appl Environ Microbiol 66: 4571-4574.

6. Bernhard AE, Field KG (2000) Identification of nonpoint sources of fecal pollution in coastal waters by using host-specific $16 \mathrm{~S}$ ribosomal DNA genetic markers from fecal anaerobes. Appl Environ Microbiol 66: 1587-1594.

7. Hongoh Y, Yuzawa H, Ohkuma M, Kudo T (2003) Evaluation of primers and PCR conditions for the analysis of $16 \mathrm{~S}$ rRNA genes from a natural environment. FEMS Microbiol Lett 221: 299-304.

8. Layton A, McKay L, Williams D, Garrett V, Gentry R, et al. (2006) Development of Bacteroides 16S rRNA gene TaqMan-based real-time PCR assays for estimation of total, human, and bovine fecal pollution in water. Appl Environ Microbiol 72: 4214-4224.

9. Ahmed W, Sawant S, Huygens F, Goonetilleke A, Gardner T (2009) Prevalence and occurrence of zoonotic bacterial pathogens in surface waters determined by quantitative PCR. Water Res 43: 4918-4928.

10. Ely E (1997) The national newsletter of volunteer water quality monitoring Volunt Monit 9:1-20.

11. Crowther J, Kay D, Wyer M (2001) Relationships between microbial water quality and environmental conditions in coastal recreational waters: The Fylde coast, UK. Water Res 35: 4029-4038.

12. Schriewer A, Goodwin KD, Sinigalliano CD, Cox AM, Wanless D, et al. (2013) Performance evaluation of canine-associated Bacteroidales assays in a multilaboratory comparison study. Water Res 47: 6909-6920.

13. Murray J, Browne W, Roberts M, Whitmarsh A, Gruffydd-Jones T (2010) Number and ownership profiles of cats and dogs in the UK. Vet Rec 166: 163168.

14. Asher L, Buckland EL, Phylactopoulos Cl, Whiting MC, Abeyesinghe SM, et al (2011) Estimation of the number and demographics of companion dogs in the UK. BMC Vet Res 7: 74

15. Traub RJ, Monis PT, Robertson I, Irwin P, Mencke N, et al. (2004) Epidemiological and molecular evidence supports the zoonotic transmission of Giardia among humans and dogs living in the same community. Parasitology 128: $253-262$.

16. Woodroffe R, Prager KC, Munson L, Conrad PA, Dubovi EJ, et al. (2012) Contact with domestic dogs increases pathogen exposure in endangered African wild dogs (Lycaon pictus). PLoS One 7: e30099.

17. Tambalo DD, Boa T, Liljebjelke K, Yost CK (2012) Evaluation of two quantitative PCR assays using Bacteroidales and mitochondrial DNA markers for tracking dog fecal contamination in waterbodies. J Microbiol Methods 91: 459-467.

18. Fiorello CV, Deem SL, Gompper ME, Dubovi EJ (2004) Seroprevalence of pathogens in domestic carnivores on the border of Madidi National Park, Bolivia. Animal Conservation. 7: 45-54.
19. Fèvre EM, Bronsvoort MC, Hamilton KA, Cleaveland S (2006) Animal movements and the spread of infectious diseases. Trends Microbiol 14: 125131.

20. Ahmed W, Stewart J, Powell D, Gardner T (2008) Evaluation of Bacteroides markers for the detection of human faecal pollution. Lett Appl Microbiol 46: 237-242.

21. Gourmelon M, Caprais MP, Ségura R, Le Mennec C, Lozach S, et al. (2007) Evaluation of two library-independent microbial source tracking methods to identify sources of fecal contamination in French estuaries. Appl Environ Microbiol 73: 4857-4866.

22. Fremaux B, Gritzfeld J, Boa T, Yost CK (2009) Evaluation of host-specific Bacteroidales 16S rRNA gene markers as a complementary tool for detecting fecal pollution in a prairie watershed. Water Res 43: 4838-4849.

23. Hall BG (2011) Phylogenetic trees made easy: a how to manual? Fourth Edition ed. USA: Sinauer Associates, Inc.

24. Tamura K, Nei M (1993) Estimation of the number of nucleotide substitutions in the control region of mitochondrial DNA in humans and chimpanzees. Mo Biol Evol 10: 512-526.

25. Morales SE, Holben WE (2009) Empirical testing of 16 S PCR primer pairs reveals variance in target specificity and efficacy not suggested by in silico analysis. Appl Environ Microbiol 75: 2677-2683.

26. Wooley JC, Godzik A, Friedberg I (2010) A primer on metagenomics. PLoS Comput Biol 6.

27. Bradley G, Carter J, Gaudie D, King C (1999) Distribution of the human faecal bacterium Bacteroides fragilis, its bacteriophages and their relationship to current sewage pollution indicators in bathing water. J Appl Microbiol 85.

28. Hussein KR, Bradley G, Glegg G (2012) An evaluation of bacterial source tracking of faecal bathing water pollution in the Kingsbridge estuary, UK. In the significance of faecal indicators in water: a global perspective, Kay $D$ and Fricker C (Eds) Royal Soc Chem Cambridge.

29. Craig DL, Fallowfield HJ, Cromar NJ (2002) Enumeration of faecal coliforms from recreational coastal sites: evaluation of techniques for the separation of bacteria from sediments. J Appl Microbiol 93: 557-565

30. Ferguson DM, Moore DF, Getrich MA, Zhowandai MH (2005) Enumeration and speciation of enterococci found in marine and intertidal sediments and coastal water in southern California. J Appl Microbiol 99: 598-608.

31. Boehm AB, Griffith J, McGee C, Edge TA, Solo-Gabriele HM, et al. (2009) Faecal indicator bacteria enumeration in beach sand: a comparison study of extraction methods in medium to coarse sands. J Appl Microbiol 107: 17401750.

32. Fricker EJ, Fricker CR (1996) Use of defined substrate technology and a nove procedure for estimating the numbers of enterococci in water. J Microbiol Meth 27: $207-210$

33. Stanfield G, Irving TE (1981) A suitable replacement for teepol 610 in the selective isolation of coliforms from marine waters and sewage. Water Res 15: $469-474$

34. Livingston SJ, Kominos SD, Yee RB (1978) New medium for selection and presumptive identification of the Bacteroides fragilis group. J Clin Microbiol 7 : 448-453.

35. Eckner KF (1998) Comparison of membrane filtration and multiple-tube fermentation by the colilert and enterolert methods for detection of waterborne coliform bacteria, Escherichia coli, and enterococci used in drinking and bathing water quality monitoring in southern sweden. Appl Environ Microbiol 64: 3079-3083

36. Nisr RB, Russell MA, Chrachri A, Moody AJ, Gilpin ML (2011) Effects of the microbial secondary metabolites pyrrolnitrin, phenazine and patulin on INS-1 rat pancreatic $\hat{~}^{2}$-cells. FEMS Immunol Med Microbiol 63: 217-227.

37. Okabe S, Okayama N, Savichtcheva O, Ito T (2007) Quantification of hostspecific Bacteroides-Prevotella 16S rRNA genetic markers for assessment of fecal pollution in freshwater. Appl Microbiol Biotechnol 74: 890-901.

38. Ahmed WA, Yusuf RY, Hasan IH, Goonetilleke AG, Gardner TG (2010) Quantitative PCR assay of sewage-associated Bacteroides markers to assess sewage pollution in an urban lake in Dhaka, Bangladesh. Can J Microbiol 56 838-845.

39. Dong B, Kim S, Hong S, Das Gupta K, Malathi E, Klein A, et al. (2007) An 
Citation: Hussein KR, Waines PL, Nisr RB, Glegg G, Bradley G (2014) Development and use of Bacteroides 16S rRNA Polymerase Chain Reaction Assay for Source Tracking Dog Faecal Pollution in Bathing Waters. Hydrol Current Res 5: 163. doi:10.4172/2157-7587.1000163

Page 8 of 8

infectious retrovirus susceptible to an IFN antiviral pathway from human prostate tumors. Proceedings National Acad Sci 104: 1655-1660.

40. Nutz S, Döll K, Karlovsky P (2011) Determination of the LOQ in real-time PCR by receiver operating characteristic curve analysis: application to qPCR assays for Fusarium verticillioides and F. proliferatum. Anal Bioanal Chem 401: 717 726.

41. Bustin SA, Benes V, Garson JA, Hellemans J, Huggett J, et al. (2009) The MIQE guidelines: minimum information for publication of quantitative real-time PCR experiments. Clin Chem 55: 611-622.

42. Klappenbach JA, Saxman PR, Cole JR, Schmidt TM (2001) rrndb: the ribosomal RNA operon copy number database. Nucleic Acids Res 29: 181-184.

43. Labrenz M, Brettar I, Christen R, Flavier S, Botel J, et al. (2004) Development and application of a real-time PCR approach for quantification of uncultured bacteria in the central Baltic Sea. Appl Environ Microbiol 70: 4971-4979.

44. Wang RF, Beggs ML, Robertson LH, Cerniglia CE (2002) Design and evaluation of oligonucleotide microarray method for the detection of human intestinal bacteria in fecal samples. FEMS Microbiol Lett 213: 175-182.
45. Shoemaker N, Vlamakis H, Hayes K, Salyers A (2001) Evidence for extensive resistance gene transfer among Bacteroides spp.and among Bacteroides and other genera in the human colon. Appl Environ Microbiol 67: 561-568.

46. Shelburne CE, Gleason RM, Germaine GR, Wolff LF, Mullally BH, et al. (2002) Quantitative reverse transcription polymerase chain reaction analysis of Porphyromonas gingivalis gene expression in vivo. J Microbiol Meth 49: 147156

47. Denecke M, Eilmus S, Röder N, Roesch C,Bothe H (2012) Molecular identification of the microbial diversity in two sequencing batch reactors with activated sludge. Appl Microbiol Biotechnol 93: 1725-1734

48. Lee C, Kim J, Shin SG, Hwang S (2006) Absolute and relative QPCR quantification of plasmid copy number in Escherichia coli. J Biotechnol 123 273-280.

49. Layton A, Cao Y, Ebentier D, Hanley K, Balleste E, et al. (2013) Performance of human fecal anaerobe-associated PCR-based assays in a multi-laboratory method evaluation study. Water Res 47: 6879-6908. 